\section{Paroxysmale nächtliche Hämoglobinurie}

\section{Helga Peter}

Marburg, Deutschland

\section{Synonyme}

PNH; schlafbezogene Hämolyse

\section{Englischer Begriff}

paroxysmal nocturnal hemoglobinuria

\section{Definition}

Erworbene chronische hämolytische Anämie infolge intravaskulärer Hämolyse, die sich im Schlaf verstärkt und die durch eine morgendliche Hämaturie auffallen kann. In schweren Fällen kann die Hämolyse zu venösen Thrombosierungen mit tödlichen Komplikationen wie Lungenembolie führen. Die Störung wird diagnostiziert mittels Säurehämolysetest oder durch Ermittlung der osmotischen Resistenz. 